\title{
Correction to: Structural and functional aspects of the interaction partners of the small heat-shock protein in Synechocystis
}

\author{
Erik G. Marklund $^{1,2} \cdot$ Yichen Zhang $^{3,4} \cdot$ Eman Basha $^{3,5} \cdot$ Justin L. P. Benesch $^{1} \cdot$ Elizabeth Vierling $^{3}$
}

Published online: 3 May 2018

(C) Cell Stress Society International 2018

\section{Correction to: Cell Stress and Chaperones \\ https://doi.org/10.1007/s12192-018-0884-3}

The original article was corrected. Table 1 contained mistakes

that needed correcting.

Justin L. P. Benesch

justin.benesch@chem.ox.ac.uk

$\bowtie$ Elizabeth Vierling

vierling@biochem.umass.edu

1 Department of Chemistry, Physical \& Theoretical Chemistry Laboratory, University of Oxford, Oxford OX1 3QZ, UK

2 Department of Chemistry - BMC, Uppsala University, Box 576, Uppsala 75123, Sweden

3 Department of Biochemistry \& Molecular Biology, University of Massachusetts, Amherst, MA 01003, USA

4 Present address: Alorica, Inc., Irvine, CA, USA

5 Present address: Department of Molecular and Cellular Biology, University of Arizona, Tucson, AZ 85721, USA 